\title{
First Day Stands Out as Most Popular Among MO0C Leavers
}

\author{
Usman Nazir ${ }^{12}$, Hugh Davis ${ }^{1}$, Lisa Harris ${ }^{1}$ \\ 1 University of Southampton, Highfield, Southampton, UK. \\ 2 Institute of Business Administration, Karachi, Pakistan. \\ * Corresponding author. email: unazir@iba.edu.pk/un2g14@soton.ac.uk
}

\begin{abstract}
The open nature of MOOCs poses new challenges for educators to engage students in their learning. It defies the traditional classroom bound learning and demands new measures to be taken that would help keep students engaged in the course. This paper studies the enrolment data of three MOOCs offered on Future Learn in 2013/14 and identifies that at any given day in its lifecycle the highest number of students leave the course on the very first day they join it. Hence, it proposes strategies such as buddying, feedback and briefing to facilitate students to stay on board and engage with the course for maximum benefit possible.
\end{abstract}

Key words: Distance Education, E-Learning, MOOCs dropout rates, MOOCs engagement.

\section{Introduction}

Massive Open Online Courses (MOOCs) are a fairly recent phenomenon in the online education industry that have garnered great support from the world leading institutions over the past three years. Partnerships among leading universities have setup platforms like Coursera, Edx, and Future Learn [1] that continue to benefit tens of thousands of students around the globe. Putting courses online and open for participation by all basically means anyone in the world who has internet access can logon to the platform and join the course. Large numbers are attracted to these courses when institutions of repute gather in delivering the material. It sounds simple but it comes with its own sets of challenges, one of them being how to retain voluntary engagement of participants in the course so they can benefit from it.

The voluntary mode of participation causes students to disengage and even leave the course when they lose interest [2]. It is no surprise that studies continue to show low completion rates [3]. Some may shrug it off and blame it on the inherent nature of MOOCs. However, with this attitude there is a risk of students losing interest too quickly to benefit from the material. Hence, in order for students to gain the maximum benefit out of the course material, engaging learning strategies must be deployed that encourage the willing student to voluntarily participate in the course.

Researchers have attributed the disengagement and dropouts to factors like: lack of time, feeling of isolation, insufficient background knowledge and skills [4], varying Learners' motivation [5], varying Learners' approach [6], and hidden costs e.g. purchase of textbooks. Solutions such as: flexible time tables [7], motivating students to complete courses through formal recognition [4] and encouraging community building [7] have been proposed and can be seen implemented for many MO0Cs. Coursera has been offering certificates at a price for people who have completed the course [8]. Many cMO0Cs encourage peer to peer learning and participation on their forums [9].

To further research, we need to drill down and study exactly when students disengage from the course. This will help us figure out and address any common pattern in behaviour. In this paper we identify the peak periods when students leave the course during the lifecycle of three MOOCs run on Future Learn in 2014. We then propose strategies on how best to engage the willing student at the point when s/he joins the course and propose further research areas in the field. 


\section{Methodology}

We studied enrolment data of three MOOCs offered on Future Learn in 2013/14. The data obtained contained the unique id of participants together with their 'enrolled' and 'unenrolled' timestamps.

The attempt was to identify any patterns as to when the participants are most likely to leave the course. For this we analysed 'enrolled' and 'unenrolled' data to identify distinct patterns, if any. To this effect, we obtained the difference in the period between 'enrolled' and 'unenrolled' timestamps to figure out how long do participants stay with the course.

\section{Data Analysis and Findings}

The charts below show how long the students who left actually stayed with the course.

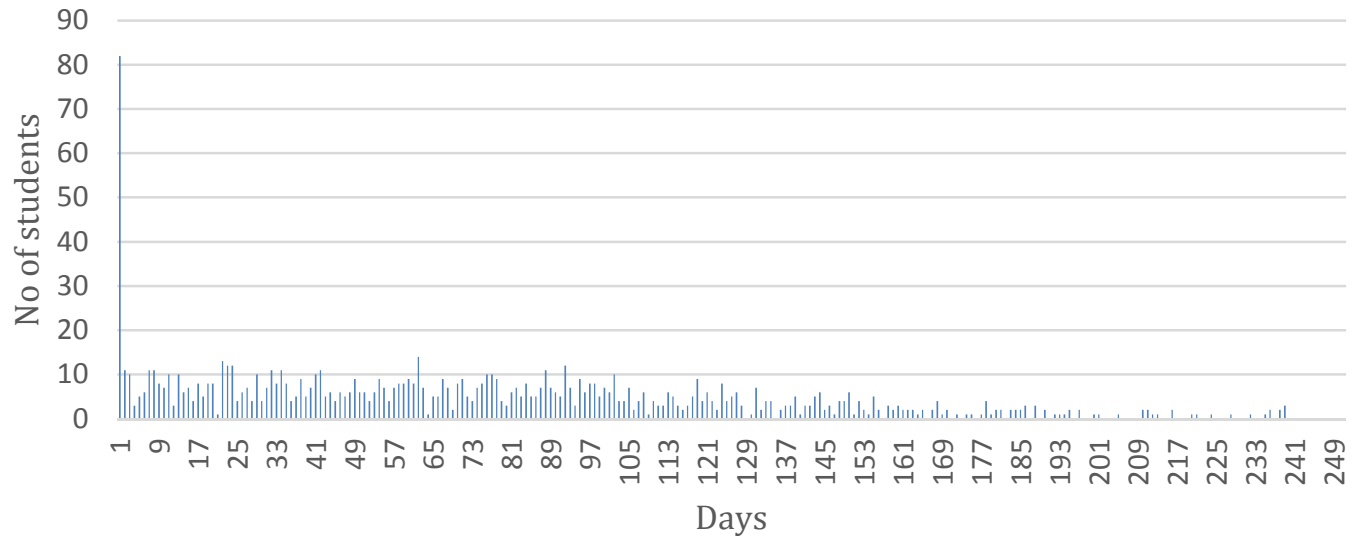

Fig. 1. Length of stay of unenrolled students

MOOC: Exploring Our Oceans (Nov 2013)

Fig. 1. above shows that 82 students left on the very first day they joined the course. The second highest score recorded for any other day is 14 .

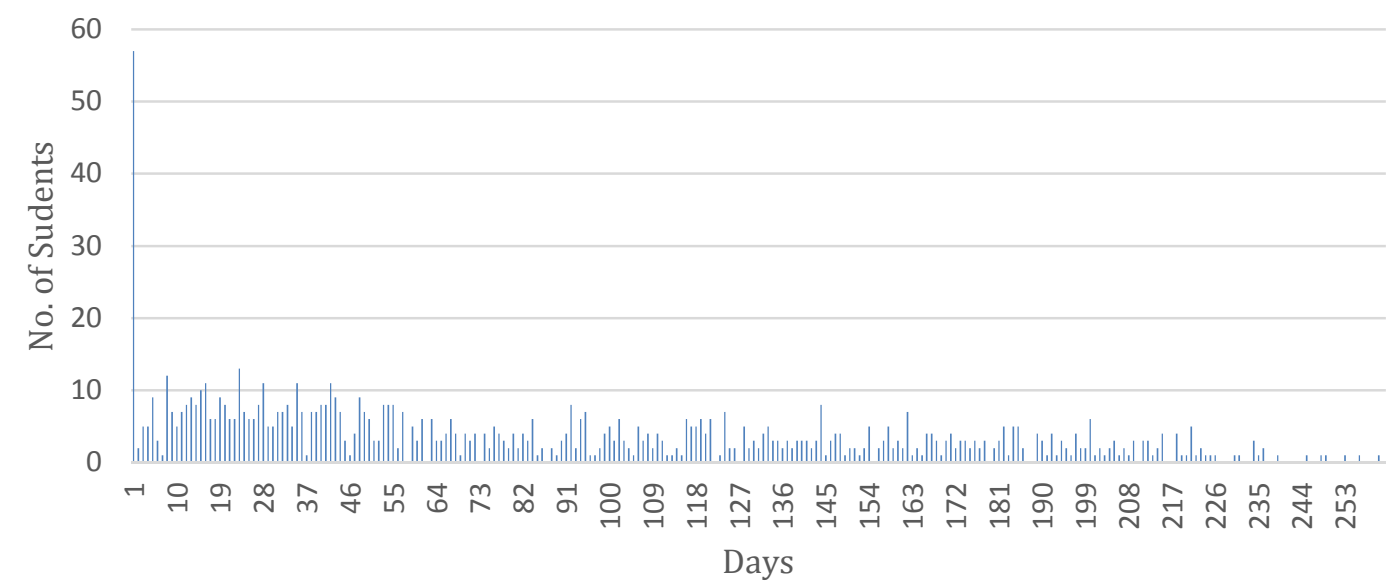

Fig. 2. Length of stay of unenrolled students MOOC: Exploring Our Oceans (Mar 2014)

Fig. 2. above shows that 57 students left on the very first day they joined the course. The second highest score recorded for any other day is 13. 


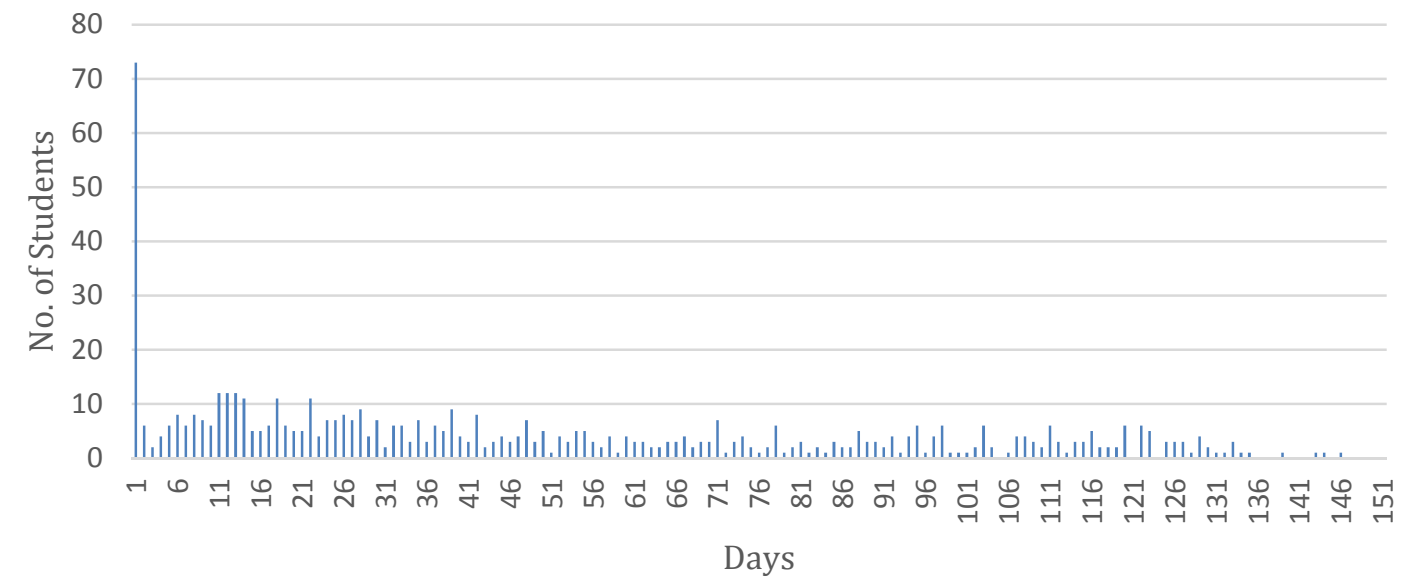

Fig. 3. Length of stay of unenrolled students MOOC: Digital Marketing (Jun 2014)

Fig. 3. above shows that 73 students left on the very first day they joined the course. The second highest score recorded for any other day is 12 .

It is clear to see that highest number of the students who leave do so during the very first day of them enrolling on the course. Hence, we must develop strategies that will help us on board students onto the course better at any point in time during its lifecycle.

\section{Discussion \& Suggestions}

Regardless of the reasons of why students leave a course it is evident that first day holds great significance in their decision to stay. We can say that this is natural and expected because registration into a course is free and since the course is open students enroll to check if they are interested in the course or not. Thus, who are not interested leave the course the very first day. However, since the enrolments and un-enrolments happen all through the lifecycle of the course it is also likely that a student enrolls into the course and fails to assimilate into the group or catch up with the progress of the course. Therefore, we must implement ways to facilitate willing students to join and benefit at any point in the course lifecycle.

Listed below are some ways to facilitate students for an easier on board process into the course:

. Briefing - it is a common practice among MOOC developers to begin the sessions with overview and wrapup with summary or conclusion. However, this is not enough as it is a cumbersome process for a newcomer to go through the many overviews and summaries of the course. In addition, there should be an up to date recap of the course at any one point in time. This will work as debrief for the new joiners and help them catch up with the course proceedings.

. Buddying - this technique has been well practiced in corporates to induct their newcomers into the organisation [10]. At the time of joining the new entrant is 'buddied up' with an old timer who can help him quickly catch up with the way things get done in the organisation. Research shows that early socialisation experiences have a long-term impact on newcomers' satisfaction, performance, and intention to stay in a group [11]. Similar strategy can be deployed in MOOCs whereby a fellow participant is suggested to the new entrant as his/er buddy. This will not only help newcomers get up to speed with the course faster but also encourage community building.

. Feedback - It is found that first time posters who receive response in an online community are more likely to post again or to post sooner [12]. Feedback engages participant with the community. Hence, MOOCs could be monitored to raise priority for feedback on first response on the forums.

\section{Further Research}

The discussion above can be furthered by surveying students' reasons of leaving. This can uncover other issues that could be tackled for better engagement of a student with the course. 
Engagement of students could also be further investigated with how students interact with the course. Cross-sectional studies could be conducted into the aspects of the course that translate into low or high engagement periods.

\section{References}

[1] White, S., et al. (2014). MOOCs: What Motivates the Producers and Participants? Communications in Computer and Information Science, (In Press), 1-16.

[2] North, S., Richardson, R., \& North, M. M. (2014). To Adapt MOOCS, or Not? That is No Longer the Question. Universal Journal of Educational Research, 2(1), 69-72.

[3] Jordan, K. (2014). Initial trends in enrolment and completion of massive open online courses. The International Review of Research in Open and Distance Learning, 15(1), 133-160.

[4] Belanger, Y. and J. Thornton (2013, February). Bioelectricity: A Quantitative Approach Duke University's First MOOC. Retrieved January 21, 2015, from

http://dukespace.lib.duke.edu/dspace/bitstream/handle/10161/6216/Duke_Bioelectricity_MOOC_Fal 12012.pdf.

[5] Yuan, L., \& Powell, S. (2013). MOOCs and open education: Implications for higher education. Cetis White Paper. Retrieved January 25, 2015, from http://publications.cetis.ac.uk/2013/667.

[6] Bruff, D. (2013). Lessons Learned from Vanderbilt's First MOOCs. Retrieved January 25, 2015, from http://cft.vanderbilt.edu/2013/08/lessons-learned-from-vanderbilts-first-moocs/.

[7] Khalil, H., \& Ebner, M. (2014). MOOCs completion rates and possible methods to improve retention-A literature review. World Conference on Educational Multimedia, Hypermedia and Telecommunications, 2014, 1305-1313.

[8] Young, J. R. (2013). Coursera announces details for selling certificates and verifying identities. Chronicle, 1, 14. Retrieved January 21, 2015, from

http://chronicle.com/blogs/wiredcampus/coursera-announces-details-for-sellingcertificates-andverifying-identities/41519?cid=at\&utm_source=at\&utm_medium

[9] Saadatmand, M., \& Kumpulainen, K. (2014). Participants' Perceptions of Learning and Networking in Connectivist MOOCs. MERLOT Journal of Online Learning and Teaching, 10(1), 16-30.

[10] Nigah, N., Davis, A. J., \& Hurrell, S.A. (2012). The impact of buddying on psychological capital and work engagement: an empirical study of socialization in the professional services sector. Thunderbird International Business Review, 54(6), 891-905.

[11] Burke, M., Kraut, R., \& Joyce, E. (2009). Membership claims and requests: Conversation-level newcomer socialization strategies in online groups. Small group research, 41(1), 4-40.

[12] Burke, M., Marlow, C., \& Lento, T. (2009). Feed me: motivating newcomer contribution in social network sites. Proceedings of the SIGCHI Conference on Human Factors in Computing Systems, ACM, 945-954.

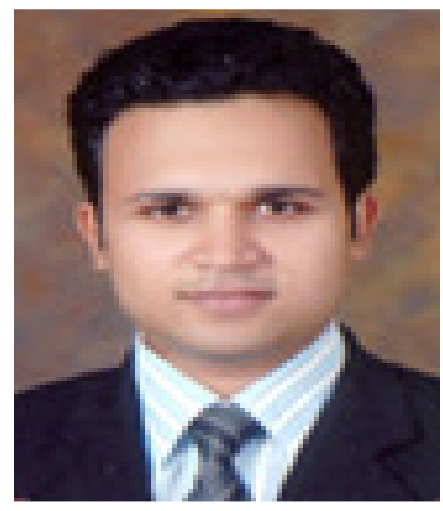

Usman Nazir is doing his PhD from the University of Southampton, UK, and is working as an Assistant Professor at IBA, Pakistan. He obtained his BSc in Computer Science and Masters of Business Administration from The City University of Hong Kong. He has well over a decade long experience in serving the education industry mostly in the Asia Pacific region. His research interests include e-Learning Management, MOOCs and Digital Literacies. 

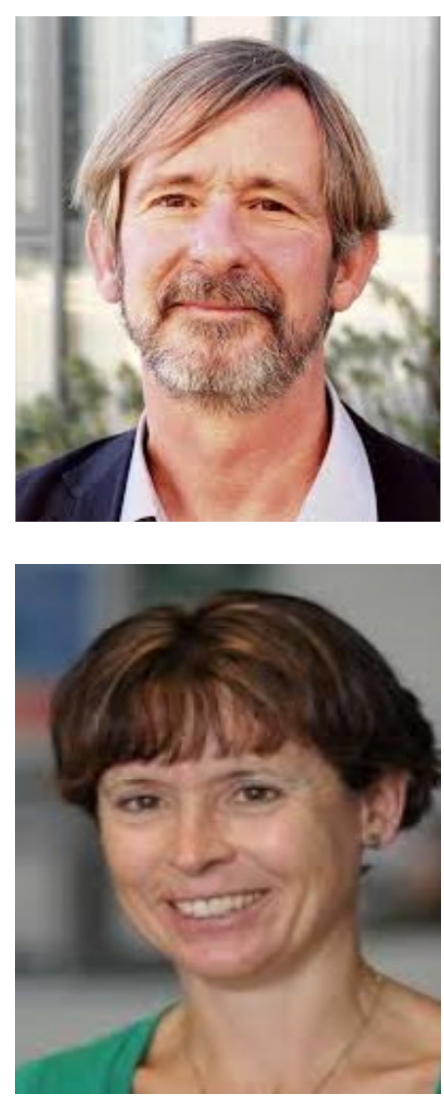

Hugh Davis is Professor of Learning Technologies in the Web and Internet Science Research Group (WAIS) at the University of Southampton, UK. He is also one of the University Directors of Education and he is the Director of the Institute for Learning Innovation and Development (ILIaD). His current research interests are all concerned with how technologies can change our perception and experience of learning. He has considerable experience of applying the outputs of research to create real change in educational practice.

Lisa Harris Associate Professor in Marketing at the University of Southampton, UK. She is also a Deputy Director of The Web Science Institute and an Associate of the Institute for Learning, Innovation and Development (ILIaD), and Programme Leader of the Digital Marketing MSc. She has developed and run a Digital Marketing MOOC in partnership with ILIaD and FutureLearn. Her research interests include Digital Literacies, MOOCs and Digital Marketing. In 2013 she achieved the Vice Chancellor's Team Award for Digital Literacies and the Student Union Faculty Award for Innovative Teaching. 